\title{
LITIGIOS SOCIALES EN TORNO A LA NOVELA DE NO FICCIÓN. ACERCA DE RECUERDO DE LA MUERTE, DE MIGUEL BONASSO
}

\section{SOCIAL DISPUTES AROUND THE NON-FICTION NOVEL. ON RECUERDO DE LA MUERTE, BY MIGUEL BONASSO}

\author{
Victoria García \\ CONICET \\ Universidad de Buenos Aires \\ victoriaggarcia@gmail.com \\ orcid: 0000-0001-7125-6722
}

Resumen: Recuerdo de la muerte, de Miguel Bonasso, se ha reconocido como una de las expresiones más relevantes de la no ficción argentina. La amplia valoración que alcanzó el texto como denuncia de la represión durante la última dictadura militar contrasta con intensas discusiones que suscitó en la posdictadura. Este artículo examina tales discusiones. Nos proponemos mostrar que la dualidad de la no ficción, que conjuga una pretensión de verdad con su faceta artística, tiene en el caso de Bonasso efectos concretos en la recepción del texto, atravesada por tensiones sociales ligadas al proceso de construcción de memoria, verdad y justicia sobre el terrorismo de Estado.

Palabras clave: no ficción; ficción; polémica; recepción; posdictadura.

Abstract: Recuerdo de la muerte, by Miguel Bonasso (1984), is recognized as one of the most outstanding expressions of Argentinian non-fiction. The popularity it achieved with its denunciation of the repression suffered during the last military dictatorship contrasts with the intense discussions it aroused during the years after the dictatorship had ended. The present article analyzes these discussions. We aim to show how the dual nature of non-fiction narrative, which attempts to reconcile historical truth with artistic creativity, has conditioned reactions to the publication of Bonasso's book, for in its reception a major role has been played by social tensions linked to the process of constructing collective memory, truth and justice in the face of State-organized terrorism.

Keywords: non-fiction; fiction; controversy; reception; postdictatorship.

Recepción: 29 de mayo de 2019; aceptación: 2 de septiembre de 2020.

D.R. () 2022. Nueva Revista de Filología Hispánica Licencia Creative Commons Attribution-NonCommercial (CC BY-NC) 4.0 International 
Recuerdo de la muerte, de Miguel Bonasso, es reconocido como una de las expresiones más relevantes de la novela argentina de no ficción. Centrado en la historia de Jaime Dri, sobreviviente de la última dictadura militar, quien en 1978 se fugó del centro clandestino de detención que funcionaba en la Escuela de Mecánica de la Armada (en adelante, ESMA), el texto se publicó por primera vez en 1984 - tanto en la Argentina como en México, donde el autor se encontraba exiliado- y gozó de amplia difusión en la transición democrática. Fue reeditado luego en múltiples oportunidades a lo largo de los años de la posdictadura.

Dentro de la obra periodística y novelística de Bonasso, Recuerdo de la muerte es, sin duda, el texto que le ha valido más reconocimiento de la crítica. Integra un canon de la literatura argentina testimonial y de no ficción (cf. Berg 1995; Coira 1995; Oliveira-Cézar 2000; Nofal 2001; García 2002; Strejilevich 2006; Longoni 2007; Goicochea 2008; Pozzoni 2012; García 2016), y se ha valorado en diversas aproximaciones a la narrativa sobre la última dictadura militar (Foster 1995; Gramuglio 2002; Reati 1985 y 2013; Gamerro 2015). Se tiende a admitir, así, el importante papel que desempeñó el texto en la denuncia de la represión desplegada durante la dictadura. Como afirma Longoni (2007, p. 50), fue un libro pionero, pues se publicó incluso antes de que los testimonios de los sobrevivientes se conociesen por medio del informe Nunca más y de sus declaraciones en el Juicio a las Juntas (1985).

Se suele caracterizar a Recuerdo de la muerte como un texto ambiguo desde el punto de vista del género, pues combina rasgos del testimonio y de la ficción (Reati 1985, p. 158; Foster 1995, p. 33; Nofal 2001, p. 57; García 2002, p. 91; Longoni 2007, p. 60; Pozzoni 2012, p. 25; Gamerro 2015, p. 537). Ciertos críticos han procurado explicar dicha ambigüedad en relación con los temas tratados en el libro. Así, para Reati (1985), la apelación a recursos narrativos de la ficción en un texto pretendido como factual queda justificada por "las características mismas de lo narrado, que si bien es historia comprobable a través de los testimonios coincidentes de los testigos, es a la vez lo suficientemente alucinante como para resistirse a toda representación ajena al discurso de lo ficticio" (p. 158). Según Longoni (2007), en cambio, la ambigüedad genérica de Recuerdo de la muerte plantea un problema ético: desde su punto de vista, el libro trata "los asuntos más escabrosos y dolorosos de vidas pri- 
vadas", las de las víctimas de la represión en la dictadura, apelando a la impunidad que le conferiría su condición literaria (p. 199).

En este artículo nos proponemos analizar las tensiones que emergen en el plano de la recepción ante un texto ambiguo como Recuerdo de la muerte. Como veremos, el libro suscitó, desde su publicación original en la transición democrática, intensos debates en los cuales tomaron parte distintos actores del proceso de producción de memoria, verdad y justicia sobre las violaciones a los derechos humanos en la dictadura. La recepción crítica del texto por parte de los protagonistas de las luchas políticas por la memoria en la posdictadura contrasta con el amplio reconocimiento que, como hemos señalado, alcanzó entre un vasto público lector que buscaba interiorizar la represión dictatorial.

El asunto de la recepción de Recuerdo de la muerte no ha sido considerado en profundidad por la crítica. Los trabajos sobre el libro que integran la dimensión de la lectura (Coira 1995; Foster 1995; García 2002; Longoni 2007) lo hacen desde la perspectiva del lector implícito en el texto, esto es, la figura lectorial que el mismo libro construye, sin tener en cuenta a sus lectores reales (Sapiro 2016, pp. 109-110). Estos últimos constituyen el objeto de nuestra indagación. Para nuestro análisis, hemos incorporado ciertas aportaciones teóricas de la filosofía y la sociología pragmáticas que, aplicadas a la reflexión sobre la ficción y la no ficción, privilegian el análisis de los modos de inscripción y funcionamiento de las obras artísticas y literarias en situaciones de producción y recepción determinadas (Schaeffer 2002 y 2013; Heinich et Schaeffer 2004; Heinich 2005; Caïra 2011; además, véase infra, "Ficción y no ficción...").

Organizaremos nuestro estudio en tres partes. En primer lugar, introduciremos nuestro análisis del libro de Bonasso en una discusión más general sobre los problemas que plantea la definición de la novela no ficción como género literario, diferenciado de la narrativa ficcional. Argumentaremos aquí que los límites de sendos géneros no remiten sólo a definiciones teóricas abstractas, sino que se instituyen en el seno de los procesos sociales - a menudo, conflictivos- en los que se producen y reciben las obras literarias. En segundo lugar, nos referiremos a Recuerdo de la muerte, considerando las circunstancias que motivaron la escritura y las características generales del texto, entre las que sobresale la ambigüedad entre lo novelesco y lo 
testimonial. Finalmente, analizaremos el proceso de recepción del libro, atendiendo en particular a las discusiones que suscitó, primero en la transición democrática de los años ochenta y después en el ámbito de la "explosión de la memoria" en los años noventa (Crenzel 2016).

Para el análisis de este proceso, nos valdremos de materiales documentales y de prensa — reseñas y comentarios críticos, entrevistas al autor, entre otros-, que complementaremos con testimonios de lectores y, en particular, de sobrevivientes de la ESMA que polemizaron sobre el libro con Bonasso. Estos testimonios, surgidos de entrevistas que hemos realizado con exdetenidos, permitirán explorar una zona relevante de la recepción del texto que ha sido poco conocida hasta ahora, en parte por la escasa difusión pública que alcanzaron las voces de los sobrevivientes en los procesos memoriales sobre el terrorismo de Estado (Jelin 2007; Longoni 2007; Feld y Messina 2014; además, véase infra, "Entre el best seller y la discusión política...") ${ }^{1}$.

Como hipótesis general de trabajo, sostenemos que en la posdictadura Recuerdo de la muerte se constituye como objeto de un debate social en el que se interroga, por un lado, la verdad sobre lo sucedido en los años setenta en la Argentina y, por el otro, las estrategias narrativas que serían apropiadas para dar cuenta de los hechos. La estrategia de la novela de no ficción adoptada por Bonasso, constitutivamente ambigua, prefigura la recepción heterogénea y hasta contradictoria que el texto suscitó a partir de la transición democrática.

\section{FiCGIÓN Y NO FICCIÓN: LÍMITES EN LITIGIO}

En El concepto de ficción, Juan José Saer sostiene:

Puesto que autobiografía, biografía, y todo lo que puede entrar en la categoría de non-fiction, la multitud de géneros que vuelven la espalda a la ficción, han decidido representar la supuesta verdad

1 Tal como señala SAPIRo (2016, p. 124), las declaraciones de los lectores representan un punto de apoyo ineludible para interrogar la "caja negra" que parece constituir la lectura, como práctica silenciosa y solitaria, y por ello reticente a la objetivación. A la vez, estos testimonios cobran relevancia en una indagación sobre la novela de no ficción, pues permiten examinar los conocimientos sobre el género y los juicios de factualidad y ficcionalidad que, de forma intuitiva, los sujetos ponen en juego en la recepción de estos textos (CAÏra 2011, p. 14; SchaefFer 2013). 
objetiva, son ellos quienes deben suministrar las pruebas de su eficacia...

La ficción, desde sus orígenes, ha sabido emanciparse de esas cadenas.

...La ficción no solicita ser creída en tanto que verdad, sino en tanto que ficción... Sólo siendo aceptada en tanto que tal, se comprenderá que la ficción no es la exposición novelada de tal o cual ideología, sino un tratamiento específico del mundo, inseparable de lo que trata (1997, p. 11).

El autor, así, establece un contraste entre ficción y no ficción basado no en la relación objetiva que mantienen con la realidad - es decir, en un fundamento semántico-, sino en el pacto de lectura que instauran: esto es, en un criterio pragmático según el cual la ficción se sustraería radicalmente de las promesas de veracidad que constriñen la narrativa factual (Schaeffer 2002 y 2013; García 2017).

De hecho, la ficción puede ser definida como un dispositivo de significación específico y como un contrato de comunicación singular, que John Searle (1975), primero, y Jean-Marie Schaeffer (2002), después, describieron recurriendo a la noción de fingimiento lúdico compartido. El dispositivo ficcional se pone en marcha, así, cuando el autor hace como si una serie de hechos tuvieran lugar, no para empujar al lector a creer en la realidad de esos hechos, sino para incentivar su inmersión en el mundo ficcional, en el marco de una relación estética (Schaeffer 2018). En virtud de ese acuerdo intersubjetivo, el carácter verdadero o falso de los enunciados que componen el relato pasaría a resultar secundario, incluso irrelevante (Schaeffer 2002 y 2013).

A menudo se afirma que, por su naturaleza lúdica, el discurso ficcional posee la capacidad de evadirse de sanciones sociales sobre su contenido referencial. Olivier Caïra (2011, p. 153) sostiene que la ficción se suele imponer como una zona de no derecho, poco permeable al juicio social sobre los modos en que en ella se representan ciertos hechos y personajes, más o menos conectados con la realidad. Astrid Erll (2012, pp. 202-204), por su parte, ha observado los privilegios que detenta la ficción en la aproximación narrativa al pasado histórico: la penetración en el mundo interior de los protagonistas de la Historia y la integración de elementos del pasado no corroborados, o incluso contrafácticos, son licencias que puede tomarse la ficción, y que resultan difícilmente aceptables en géneros factuales como las memorias, el testimonio y el relato historiográfico. 
Sin embargo, esta impunidad que se arroga la ficción, asociada a su carácter pragmático, no siempre se admite sin debates en el seno de la sociedad. A veces, las prerrogativas del discurso ficcional se vuelven objeto de controversias (Lavocat 2016, p. 276). En esta línea, estudios recientes han señalado la importancia de considerar los procesos de producción y recepción de las ficciones en contextos específicos, atendiendo a los modos en que los actores del Estado y de la sociedad civil intervienen en la definición de los límites de la ficción (Heinich 2005): esto es, su delimitación como un tipo de discurso específico, con características propias que lo distinguirían del terreno de lo factual, pero también el establecimiento de derechos y deberes que se adjudican a la ficción en contextos históricos y culturales específicos (Sapiro 2013). Los procesos judiciales montados contra obras ficcionales revisten especial interés a este respecto. En ellos no sólo se debaten las facultades que se conceden o se deniegan a la ficción cuando ésta se "entromete" con el mundo real, sino también se interroga el estatuto mismo de lo ficcional, en ocasiones poniendo en juego definiciones elaboradas por la teoría literaria (Heinich 2005; Caïra 2011, pp. 153 ss.; Sapiro 2013 y 2016, pp. 113-114; Lavocat 2016, pp. 273 ss.).

Ahora bien: cuando no se trata ya de ficción, sino de narrativa de no ficción o factual ${ }^{2}$, las condiciones de escritura y de lectura son diferentes. El carácter factual de una narrativa involucra constitutivamente su exposición a ser evaluada en términos de su mayor o menor adecuación a los hechos reales que conforman su objeto. Como afirma Marie-Laure Ryan (2004), en los relatos factuales el mundo textual es juzgado "en términos de la precisión con la que reproduce un mundo externo de referencia que el lector conoce gracias a otros canales de informa-

${ }^{2}$ La denominación "narrativa factual" suele preferirse en la bibliografía especializada, como intento por conceptualizar estas producciones textuales eludiendo la definición por la negativa que introduce el nombre no ficción y subrayando, antes bien, que se trata de narrativas referidas a hechos reales (GenetTe 1991; SchaefFer 2013; Lavocat 2016; Fludernik \& Ryan 2019). Si bien la noción de factualidad estaba presente ya en la definición "bautismal" del género que propuso Truman Capote — quien caracterizó la novela de no ficción como "a narrative form that employed all the techniques of fictional art but was nevertheless immaculately factual' (en Plimpton 1966)-, fue el término no ficción el que alcanzó mayor notoriedad y difusión como nombre de género (SchaefFer 2006), mientras que los usos de la noción de factualidad se circunscriben, en rasgos generales, al discurso académico sobre la literatura y las artes. 
ción" (p. 119). Es por esto que, como señalaba Saer, los textos factuales deben ocuparse de "suministrar pruebas de su eficacia” y de su rigor histórico: deben esforzarse en demostrar que la versión de los hechos que ofrecen mantiene correspondencias claras con ese mundo externo al texto que se tiene por real, y que orienta no sólo a los lectores, sino también a los autores, al lidiar con narrativas factuales ${ }^{3}$.

Si hablamos de novela de no ficción, es decir, de narrativa factual escrita con pretensiones y formas literarias, la cuestión resulta aún más compleja, pues el propósito de dar cuenta veraz de ciertos hechos que ostenta un relato factual no es fácilmente compatible con la propensión creativa de la literatura. En este sentido, la novela de no ficción plantea un "entrecruzamiento de códigos", como lo llama Berg (1995, p. 95), y no simplemente un apego a la verdad objetiva, como denunciaba Saer. La crítica a menudo ha observado esta dualidad del género. Para Amar Sánchez (2008), las tensiones entre la intención de referir ciertos hechos reales y la búsqueda creativa que atraviesan el género se resuelven en la concepción particular de la verdad que promueven estos textos, asociada íntimamente a la perspectiva subjetiva de quien narra: "la verdad", en estas narrativas, "es la verdad de los sujetos que construyen... un relato" (p. 41). Javier Cercas (2016, p. 34), quien en las últimas décadas ha desarrollado un proyecto literario en torno de lo que denomina "novela sin ficción", señala por su parte que el género persigue dos verdades diferentes: una histórica, que es factual, abstracta y particular, y otra literaria, que es moral, abstracta y universal. En la contradicción que se teje entre ellas residen, para el autor, no tanto los problemas del género como sus potencialidades. A la vez, Cercas sugiere que la contienda entre sendas facetas de la "novela sin ficción" es asimétrica, pues en definitiva en estos relatos la construcción de una verdad histórica tiende a someterse a los objetivos de la creación literaria - "es posible", reconoce sobre su producción narrativa, "que la verdad histórica esté al servicio de la verdad literaria”- (p. 35).

Las soluciones narrativas que los autores de no ficción adoptan como formas de lidiar con la tensión constitutiva de estos

${ }^{3}$ CaÏra (2011, p. 39) sostiene que, en rigor, ese mundo externo de referencia no es sino una construcción social, elaborada sobre la base de versiones diferentes de la realidad, a partir de cuyo cotejo se establecen objetos y acontecimientos que se consideran reales en ciertas épocas y ámbitos culturales. 
textos, lejos de ser uniformes, varían en las distintas expresiones del género. Por lo demás, no necesariamente tales soluciones habrán de resultar satisfactorias ante los lectores. En efecto, la historia de la no ficción como género deja ver diversas situaciones de recepción polémica, en las que se ponen de manifiesto los problemas que acarrea el intento por conjugar ciertas pretensiones estéticas con la persecución de la verdad fáctica. No podemos detenernos en esta cuestión aquí. Baste remitir al ejemplo del fundador del género en Estados Unidos, Truman Capote. Si con la célebre In cold blood el autor recibió críticas por haber tergiversado los hechos reales desde una perspectiva condescendiente con uno de los implicados en el crimen, Perry Smith (Tompkins 1966) ${ }^{4}$, años más tarde afrontó acusaciones mucho más graves sobre "La Côte Basque, 1965", relato que concibió como parte de su novela inconclusa, Answered prayers. El texto generó un amplio rechazo entre integrantes de la alta sociedad neoyorkina y amistades del escritor, cuyas historias íntimas salieron a la luz con la publicación del relato (Marsh 2013). Según Clarke (2006, p. 516), biógrafo de Capote, la controversia sobre "La Côte Basque, 1965" fue el inicio del fin de su carrera literaria ${ }^{5}$.

En resumidas cuentas, la novela de no ficción se muestra como un espacio de tensiones, cuyos límites no se definen únicamente a partir de opciones estéticas de los autores, sino en la relación que se teje entre éstos y los lectores. En el caso que nos ocupa, veremos que el intento de Miguel Bonasso por hacer

${ }^{4}$ Como lo señala Pettersson (2005, p. 89), Capote salió airoso de la polémica sobre la factualidad de In cold blood, pues la mayoría de los críticos consideró que las desviaciones que el texto introducía sobre los hechos comprobables no eran lo suficientemente relevantes para poner en entredicho la veracidad global del relato.

${ }_{5}^{5}$ En el contexto latinoamericano, probablemente el caso más célebre de recepción polémica de un texto de no ficción sea la controversia que se suscitó en torno a Me llamo Rigoberta Menchú y así me nació la conciencia, de Elizabeth Burgos (1983), a partir de los cuestionamientos publicados por el antropólogo estadounidense David Stoll, que ponían en entredicho la veracidad del relato de la líder indígena guatemalteca (cf. Morales 2001 y Picornell 2015). En el ámbito argentino, se destacan los casos de La masacre de San Patricio de Eduardo Kimel (1989), que fue demandado por calumnias e injurias por uno de los involucrados en la historia (LORETI y LozANo 2014), y el de Plata quemada de Ricardo Piglia (1997), que atravesó un pleito jurídico impulsado por uno de sus "personajes" por violación del derecho a la intimidad, usurpación de nombre y daño moral (VINCENTi 2015, p. 21). 
compatibles veracidad histórica y despliegue creativo en Recuerdo de la muerte encontró un límite en distintas críticas de las que fue objeto el libro, centradas en el modo en que se acercaba a la represión en la última dictadura militar. Las tensiones que atravesaron la recepción del texto pusieron de relieve problemas semejantes a los que, en su momento, afrontó Capote: por un lado, se discutió la mayor o menor exactitud con la que el autor daba cuenta de una historia que presentaba como real; por el otro, se cuestionaba el hecho mismo de que revelara ciertos aspectos de aquella historia, sin el consenso de los involucrados y en el contexto complejo que representaba la transición democrática.

\section{LA "NOVELA-REAL" DE BonASSO: GÉNESIS y ESTRUCTURA DE UN TEXTO AMBIGUO}

Recuerdo de la muerte trata sobre la experiencia como superviviente de Jaime Dri durante la dictadura, luego de su secuestro en diciembre de 1977. Dri era miembro en ese momento del Consejo Superior de la organización Montoneros. Después de su captura, permaneció secuestrado en distintos centros clandestinos de detención: la ESMA, la Quinta de Funes, la Escuela Magnasco, La Intermedia y, por último, nuevamente la ESMA. Durante una salida hacia la frontera con Paraguay en julio de 1978, a la que fue llevado por sus captores, logró escaparse (Dri 1978). Posteriormente, salió hacia el exilio. Entre fines de 1979 y comienzos de 1980, fue parte de las discusiones que se produjeron en Montoneros sobre la llamada "Contraofensiva Estratégica” de la organización. Dri y otros militantes, entre los que se contaba Bonasso, elevaron una serie de críticas a la conducción, luego de la primera fase de la Contraofensiva. En abril de 1980, rompieron con el partido para conformar otra organización, que se denominó Montoneros 17 de octubre (Bonasso 1994, p. 393; Confino 2015).

La nueva organización tuvo, al decir de Bonasso (2001a, p. 31), "una vida muy fugaz". Ya por entonces, el autor imaginaba un libro que tendría como protagonista a quien había sido su compañero de militancia:

Desde el momento mismo en que se consagró nuestra ruptura con la Conducción Nacional de Montoneros supe que había que 
contar la terrible historia del Pelado Jaime Dri en la Escuela de Mecánica de la Armada.

...Mucho antes, a fines de 1978, cuando el Pelado Dri logró escaparse de la ESMA y del país, la posibilidad de convertir su historia en libro (o incluso en un film) me excedía. Estaba convencido de que había que contarla, pero pensaba en escritores consagrados para darle rápida difusión y ayudar a nuestra lucha contra la dictadura militar. A tal fin me entrevisté tres veces con Gabriel García Márquez... Yo quería que el ilustre Gabo escribiera una novela con la fuga del Pelado...

Por suerte para mí, todo quedó en agua de borrajas... Entonces en 1980, cuando hablamos de regreso de Managua a México, tras romper para siempre con Pepe Firmenich, le dije al Pelado que la historia había que contarla y que yo estaba dispuesto a hacerlo (Bonasso 2001, pp. 32-33).

El relato de Bonasso es significativo porque expone las condiciones en las que el autor concibió Recuerdo de la muerte: el libro aparece como un corolario de la ruptura con Montoneros, que compartió con Dri; de allí que numerosas críticas a la organización atraviesen su enfoque narrativo (Nofal 2001; Pozzoni 2012). Más aún: el distanciamiento del autor de la que había sido su organización política da lugar, en este relato de origen del libro, a un acercamiento a la esfera literaria, primero mediado por la figura del escritor consagrado, García Márquez, y luego realizado en el proyecto de Recuerdo de la muerte . $^{6}$.

El autor destaca, además, la fuga del centro clandestino de detención como leitmotiv de la historia que había de ser contada. Hay que notar, en este sentido, que Dri fue el único detenido de la ESMA que consiguió fugarse y sobrevivir, y uno de los pocos prisioneros que lograron escapar exitosamente de centros clandestinos de detención durante la dictadura (Calveiro 2008, pp. 125-128). La singularidad del caso de Dri parecía volverlo, desde la perspectiva del autor, novelable. Más aún, podía dotar el relato de Dri de una legitimidad de la cual, durante la transición democrática, no gozaba la mayoría de los exdetenidos sobrevivientes. Feld y Messina (2014) se han referido a estos sobrevivientes como testigos denegados: para ellos, el mismo

${ }^{6}$ Bonasso ha señalado que Recuerdo de la muerte constituyó para él la recuperación de una vocación literaria que había pospuesto a causa de su actividad militante: "en el fárrago de la tremenda actividad política de los años 70 postergué y enterré mi vocación literaria... Con Recuerdo de la muerte retomé, a través de lo político, la vieja vocación literaria” (en BARDINI 1984, p. 64). 
hecho de la supervivencia pesaba como un estigma, pues se sospechaba que habían preservado sus vidas por colaborar con la represión dictatorial (cf. también Jelin 2007 y Longoni 2007) 7 .

El libro fue elaborado entre 1981 y 1983 , sobre la base de entrevistas que Bonasso mantuvo con Dri en México, donde ambos se encontraban exiliados (Bonasso 1994, p. 464). Las entrevistas con Dri no aparecen transcriptas en el libro, sino noveladas. En efecto, el texto de Recuerdo de la muerte se configura como un relato heterodiegético compuesto con técnicas novelísticas clásicas (Longoni 2007, p. 64). Por momentos, sin embargo, irrumpe en el relato un narrador en primera persona, que remite al propio Bonasso, y cuya función narrativa reside en tematizar el proceso de escritura del libro, signado por la situación de exilio que aquél compartió con su informante (García 2002, p. 95; Strejilevich 2006, p. 93) .

El eje de la narración se constituye a partir de la historia de Dri. Sin embargo, no en todas las escenas su personaje está presente: el autor incluye episodios protagonizados por otros detenidos -incluso algunos que, para el momento en que se escribe el libro, han muerto (cf., por ejemplo, "Tucho", centrado en Tulio Valenzuela, y Raquel Negro) - y otros protagonizados por represores (cf. "El Tigre y el Almirante"). Puesto que Dri no pudo haber conocido estas escenas, cabe interpretarlas como recreaciones ficcionales (Foster 1995, p. 35; Strejilevich 2006, p. 91; Longoni 2007, p. 63). Ahora bien, no hay marcas en el relato que permitan identificar ese estatuto diferencial. El relato heterodiegético funciona, en conjunto, como un recurso de verosimilitud, que unifica bajo una misma modalidad narrativa hechos y personajes configurados, en rigor, a partir de métodos diversos.

${ }^{7}$ El hecho de que Dri se haya fugado de su captura en la ESMA constituye un factor relevante de su legitimación social como testigo y de la construcción de su "carrera testimonial", al decir de Fleury y Walter (2012). Ya en 1980, aparecía en la prensa mexicana como "el montonero que escapó de la pesadilla” (FAzıo 1980). En el ámbito argentino, la historia de su fuga cobró carácter público desde los inicios de la transición democrática: en junio de 1984, La Semana publicó una entrevista hecha a Dri en la que éste refirió su experiencia como superviviente, titulada " «o me escapé de la Escuela de Mecánica de la Armada»" (CAstellanos 1984).

8 "Perdón por meterme. No puedo evitarlo... Este capítulo es uno de los que me han dado más trabajo. Y quiero contarle al lector cómo está naciendo. En un anochecer de julio de 1983, en la ciudad de México..." (BONASSO 1984a, p. 348). 
De manera semejante, la historia del Tigre Acosta - uno de los represores de la ESMA - y la prisionera "Pelusa" no se atiene de manera estricta a la base factual del libro. "Pelusa" se involucra en una relación afectiva con Acosta. Condensa, así, la acusación de traición que Bonasso despliega sobre militantes detenidos que habrían colaborado con la represión, y la refuerza con un sesgo de género, al culpar a la mujer que habría entregado su cuerpo a los represores (Longoni 2007). Estrictamente, sin embargo, este personaje no tiene correlato con ninguna de las detenidas que pasaron por la ESMA. Su introducción supone un desvío dentro de un texto postulado como factual, en el cual, además, los protagonistas se identifican por los nombres que llevaban en la vida real - ya sus alias militantes o sus nombres completos. Bonasso (1999 y 2014, p. 34) aclararía, sólo años después de la publicación del libro, que había apelado al nombre falso de "Pelusa" para proteger la identidad de una detenida en la cual se había inspirado para contar la historia. Aun así, a lo largo del proceso de circulación del texto la figura de "Pelusa" provocaría, como veremos, malentendidos diversos.

En la "Crónica final", que funciona a modo de posfacio del libro, el autor lo caracteriza como una "novela-real o realidad-novelada" (Bonasso 1984a, p. 397), que cuenta un hecho "rigurosamente cierto" y se apoya en "una base documental enorme y concluyente" (p. 404). La filiación con la tradición de la novela de no ficción, y con su doble propósito, a la vez factual y creativo, es aquí evidente. Según Bonasso, optó por una novela de estas características porque buscaba "desenterrar ciertos arcanos que a veces se niegan a salir dentro de las pautas más racionales de la crónica histórica, el testimonio de denuncia o el documento político" (id.). Además, en una entrevista que concedió en oportunidad de la publicación original en la Argentina, añadió que el recurso a la narración novelesca permitiría popularizar los hechos: "quiero que... sean populares, que circulen, que la gente tenga una vivencia del horror" (en Bardini 1984, p. 63) .

${ }^{9}$ En la misma entrevista, el autor explicita la ligazón de su libro con la tradición de la no ficción, remitiendo a Truman Capote y sobre todo a Rodolfo Walsh como sus referentes: "La novela se inscribe en un género que los norteamericanos llaman nonfiction novel y que se puso de moda con Truman Capote. Pero antes de Truman Capote, en Argentina teníamos al creador de ese género..., que era Rodolfo Walsh... Walsh fue un precursor y un maestro" (ibid., p. 64). 
Por lo demás, el autor aclara que el recurso a la novela no se derivaba de un intento deliberado por falsificar la historia: "la voluntad de novelar no encubre... el designio de modificar los hechos" (Bonasso 1984a, p. 404).

Ahora bien: las dos facetas de la "novela-real o realidad-novelada" no son sencillamente amalgamables. El compromiso de factualidad formulado por el autor resulta tensionado por licencias creativas que él mismo se atribuye en la reconstrucción de los hechos: recreación de escenas que Dri no pudo haber presenciado ni conocido, y hasta la introducción de un personaje ficticio. Esta tensión se pondrá de manifiesto en el proceso de recepción del libro. Como hemos anticipado, dos fueron los ejes básicos de las discusiones que suscitó: por un lado, el valor de verdad del relato - pues se imputaban al autor ciertas inexactitudes y parcialidades en el reporte de los hechos-; por el otro, el (ab)uso estético que implicaba hacer literatura con las vidas reales de quienes habían atravesado la difícil experiencia de la detención clandestina en la dictadura y que, sin haberlo consentido, se vieron convertidos en "personajes" de la novela de Bonasso.

ENTRE EL BEST SELLER Y LA DISCUSIÓN POLÍTICA.

RECUERDO DE LA MUERTE EN LA TRANSICIÓN DEMOCRÁTICA

En los primeros años de la democracia, Recuerdo de la muerte fue en gran manera reconocida como una fuente de información valiosa sobre la represión clandestina en la dictadura. Fuera de la Argentina, se tradujo a varios idiomas, obtuvo críticas favorables en la prensa ${ }^{10}$ y en 1988 ganó el premio Rodolfo Walsh en

10 En Proceso de México, Carlos Fazio (1984) destaca que Recuerdo de la muerte ofrece "un análisis realista de la derrota del Movimiento Montonero", mientras que en Le Monde Diplomatique, Ignacio Ramonet (1984) valora positivamente la forma novelesca que adopta el relato y el estilo del autor: "La forme romanesque et le style adopté, sobre, simple, dépourvu d'affectation, s'imposaient pour atteindre plus largement l'opinion publique et, d'une certaine façon, pour mieux faire comprendre les dimensions non seulement politiques mais aussi psychologiques et culturelles de la récente tragédie argentine”. En la contraportada de la edición de 1988, se recogen además comentarios elogiosos de De Volksrant de Holanda, La Vanguardia de España y Le Monde de Francia (cf. BonAsso 1988). La Edición definitiva agrega comentarios favorables publicados en The Village Voice de Estados Unidos y el Corriere della Sera de Italia (cf. Bonasso 1994). 
la Semana Negra de Gijón. En la Argentina, aunque su reconocimiento en la prensa fue limitado - circunscrito a algunos medios comprometidos con la denuncia de las violaciones a los derechos humanos en la dictadura- ${ }^{11}$, agotó varias ediciones en librerías ${ }^{12}$ y se recibió con interés entre lectores que buscaban informarse sobre los sucesos vinculados al terrorismo de Estado -y, en algunos casos, contribuir activamente con su esclarecimiento ${ }^{13}$. El libro llegó incluso a la esfera judicial, cuando Jaime Dri lo incorporó a su testimonio contra el excomandante Massera - responsable de los crímenes de lesa humanidad cometidos en la ESMA- (Longoni 2007, p. 62). Fue, además, acogido con aprobación por familiares de víctimas que promovieron el enjuiciamiento a los responsables de la represión. Una carta a Bonasso de la asociación de Familiares de Desaparecidos y Detenidos por Razones Políticas saludó en 1988 la segunda edición del libro, que calificaron como "un valioso testimonio y denuncia de este horror que fue en nuestro país la desaparición forzada de personas" (Guagnini y Lois 1988).

Ahora bien: entre los sobrevivientes de la ESMA la recepción del texto de Bonasso fue menos favorable. El autor recibió críticas de algunos exdetenidos que cuestionaron los modos en que había tratado la realidad del centro clandestino de deten-

${ }^{11}$ La revista Humor publicó un adelanto del libro en enero de 1984 (BonAsso 1984) y una entrevista a Bonasso en marzo del mismo año (BARDINi 1984). Además, La Semana se refirió al libro y a su notable éxito de ventas en la entrevista a Dri publicada en junio, ya citada (CASTEllanos 1984). En 1985, El Porteño publicó un artículo de Bonasso que daba continuidad a la investigación de Recuerdo de la muerte (Bonasso 1985; véase infra, nota 12). Ya en 1988, Página/12 saludó la reedición de la novela con una crónica de la presentación, en la que participaron Osvaldo Bayer y Juan Sasturain (BLAusTEIN 1988). Años después, Bonasso (2014) se referiría a la limitada difusión que la prensa de la transición democrática dio a su libro en los siguientes términos: "Recuerdo de la muerte se había publicado en abril de 1984, en medio del silencio casi total de la prensa argentina” (p. 11).

${ }^{12}$ El libro agotó en diez días una primera tirada de cinco mil ejemplares (cf. Castellanos 1984); en total, llegó a vender doscientos mil (LongOni 2007, p. 51). Para 1988, había alcanzado su cuarta edición (cf. Bonasso 1988).

${ }_{13}$ Uno de ellos, de hecho, se involucró en una investigación personal que profundizaba y rectificaba alguna información del libro, vinculada con la ubicación y las características de los centros clandestinos de detención que habían funcionado en la provincia de Santa Fe. Bonasso ofreció los resultados de la investigación de este lector en una nota publicada en $E l$ Porteño, en 1985, y más tarde los sintetizó en el paratexto añadido a la Edición definitiva (1994, pp. 448 ss.). 
ción. En el verano de 1984, él y Dri discutieron el manuscrito con Graciela Daleo y Andrés Castillo en Madrid, y con Alberto Girondo en París (Bonasso 1994, pp. 465 ss., y 2014, pp. 30 ss.). Todos ellos aparecían en el libro, con mayor o menor grado de protagonismo.

Las discusiones de Bonasso con exdetenidos de la ESMA que figuraban como "personajes" en el libro tomaron carácter público sólo años después de la edición original y desde la perspectiva del autor, quien las reseñó sucintamente en la Edición definitiva del libro (1994) y las amplió luego en crónicas publicadas en la revista 3 puntos (2001 y 2001a), así como en su libro Lo que no dije en "Recuerdo de la muerte" (2014). Según Bonasso, las críticas de los sobrevivientes apuntaron a tres aspectos principales. En primer lugar, al hecho de que Recuerdo de la muerte construía una figura heroica en torno de Jaime Dri, sobre la base de una fuga que, como estrategia de supervivencia, no podía glorificarse, sino más bien cuestionarse, pues se había tratado de una decisión individual que había puesto en riesgo la vida de otros detenidos: "En general... seguían sin perdonarle a Jaime que se hubiera escapado" (1994, p. 466), afirma el autor a este respecto. En segundo lugar, los sobrevivientes criticaron la divulgación de las identidades de los detenidos en el libro y sus consecuencias en el contexto de la transición democrática. En tercer lugar, se refirieron al carácter novelado del libro y al abuso que suponía hacer literatura con el horror que habían atravesado los prisioneros durante la detención clandestina: "apuntaban... a sugerir que había convertido la tragedia de tantos en un thriller para volverme rico y famoso" (Bonasso 2014, p. 26).

El hecho de que la palabra de los sobrevivientes sobre el texto de Bonasso se haya conocido inicialmente por la mediación del propio autor no es sino un corolario de las condiciones sociales que han regido la producción de testimonios sobre la dictadura argentina, a las que ya hemos aludido en relación con la concepción del texto - pues Dri, como sobreviviente, no habla en el libro sino por intermedio de Bonasso. En esta línea, las dificultades de los sobrevivientes para inscribir su testimonio en la esfera pública, ligadas a los estigmas y las acusaciones de traición y colaboracionismo que pesaban sobre ellos (Longoni 2007; Feld y Messina 2014), constituyen un factor relevante tanto del proceso de elaboración del texto como de las formas en que se desplegaron las polémicas sobre él en los inicios de la democracia. 
A la vez, el hecho de que las discusiones suscitadas en torno a Recuerdo de la muerte sólo se hayan divulgado a posteriori responde, en parte, a que la publicidad de ciertos hechos tratados en el libro se encontraba en el centro del debate. La cuestión de las identidades de los personajes, que fue uno de los ejes de la discusión, resulta fundamental en este punto. No sólo se trataba de la inclusión de los nombres reales de los detenidos en el libro sino, además, de su ligazón explícita con la militancia en Montoneros. Como ha señalado Reati (2013, p. 86), Recuerdo de la muerte se aparta de las características de la mayoría de las narrativas sobre la dictadura producidas en la transición democrática, en las que predominó la representación de los desaparecidos como víctimas inocentes del terrorismo de Estado (Crenzel 2010). Ello constituía una estrategia de legitimación de las denuncias de las violaciones a los derechos humanos, en un entorno signado por la ambivalencia de las políticas del gobierno alfonsinista, que oscilaron entre la voluntad de castigo hacia los militares y la equiparación entre el actor militar y las organizaciones guerrilleras como responsables por la violencia del pasado (Franco 2014, p. 37). En este contexto, cobran sentido las críticas de los sobrevivientes a Bonasso. Su impugnación a la divulgación de las identidades militantes de los protagonistas del libro, durante la transición democrática, no podía tener lugar sino en la esfera privada o, mejor, en la clandestinidad en la que aquéllos habían desarrollado su actividad política, y en la que buscaban preservarse frente a la condena oficial.

La perspectiva de los sobrevivientes, despojada de la mediación del escritor, resulta relevante para comprender el rechazo que el enfoque de Bonasso suscitó en algunos de ellos. Como hemos señalado en la introducción, las entrevistas ofrecen una herramienta importante para los fines de la reconstrucción de dicha perspectiva.

Sobre la focalización del libro en la figura de Dri y en su fuga, hay que decir que las posiciones de los exdetenidos acerca del significado de la huida como estrategia de supervivencia son dispares. Para algunos, efectivamente representaba una salida individual que rompía con los acuerdos colectivos estipulados en la detención clandestina. Juan Gasparini, en un pasaje de su libro Montoneros: final de cuentas (1988), que introduce implícitamente una polémica con Recuerdo de la muerte, afirma: "Rompiendo el acuerdo tácito que nos unía allí dentro (donde anteponíamos la liberación colectiva con dignidad a la fuga 
individual), [Dri] corrió hacia Asunción... exponiendo a quienes allí quedábamos a la «boleta» reiteradamente prometida para ocasiones como esa" (p. 111) ${ }^{14}$. Para otros sobrevivientes, en cambio, la fuga constituía una opción válida y hasta una tarea necesaria de los militantes en cautiverio: "Yo creo que todos nosotros tenemos la obligación de fugarnos; no el derecho, la obligación de fugarnos", señala a este propósito Andrés Castillo $^{15}$.

Más allá del significado ético o político que los sobrevivientes de la ESMA atribuyeran a la huida de Dri, la crítica que plantearon a Bonasso apuntaba, sobre todo, a la parcialidad en la que había incurrido el autor al retratar la detención clandestina en la ESMA tomando como base únicamente su testimonio. A este respecto, Graciela Daleo afirma: "Si él [Bonasso] hubiera querido, hubiera podido conversar con los distintos compañeros". Como consecuencia de la parcialidad del enfoque, la representación de la detención clandestina eludía aspectos cruciales del funcionamiento del dispositivo concentracionario: "le dijimos [a Bonasso]: los cinco mil compañeros que pasaron por la ESMA y que no estuvieron en la «Pecera» o en el «Sótano» no aparecen [en el texto]"16, evoca Daleo, y agrega que el uso sistemático del terror por parte de los agentes de la represión estaba ausente del libro: "los marinos que a mí me aterrorizaban... no los veía" ${ }^{17}$. Así, el proceso de supervivencia en la

${ }^{14}$ El propio Bonasso interpreta como polémico el comentario de Gasparini e incluye una réplica en la Edición definitiva de Recuerdo de la muerte (1994, p. 466).

${ }^{15}$ Esta y las demás citas de Andrés Castillo proceden de una entrevista personal que me concedió en Buenos Aires el día 3 de diciembre de 2018. Si para Castillo la fuga de la prisión política representa un deber militante, para Pilar Calveiro (2008, p. 113) —sobreviviente de la ESMA y autora de Poder y desaparición - demuestra más bien un poder o una capacidad de resistencia de los detenidos ante el dispositivo concentracionario, capacidad que se desplegó en la forma de diversas estrategias de supervivencia y reafirmación identitaria.

${ }^{16}$ Se refiere a dos de las salas del centro clandestino de detención que funcionaba en la ESMA. Otros espacios de reclusión de prisioneros eran "Capucha" y "Capuchita". Véase la descripción del centro clandestino que figura en el Nunca más (CONADEP 1984, p. 83), elaborada a partir de testimonios de sobrevivientes.

${ }^{17}$ Todas estas citas de Daleo, como las que se ofrecen más adelante, corresponden a una entrevista personal que tuve con ella en Buenos Aires el 20 de octubre de 2016. Por lo demás, el mismo Dri señaló que el enfoque del libro resultaba parcial como aproximación al dispositivo represivo de la 
ESMA tendía a reducirse a una "guerra de aparatos": los marinos y los militantes secuestrados ${ }^{18}$.

Otro eje importante de discusión fue, como ya señalamos, el carácter novelado del libro. Andrés Castillo afirma a este respecto que las licencias que se había tomado el autor en su aproximación a los hechos reales se derivaban de decisiones individuales, ajenas al compromiso político que había mantenido con Montoneros: "A mí lo que me molestó fue lo novelado... Puso condimentos de novela que no le constan... Si esto lo hubiese escrito un escritor está en su derecho a hacerlo. Él como militante tenía obligaciones con su militancia”. Para Castillo, la verdad sobre la detención clandestina en la ESMA se construía colectivamente y, más aún, constituía una tarea política, unida a la militancia en Montoneros que el exdetenido había compartido con Bonasso y Dri. De allí que la crítica a los aspectos novelados del libro se conectase con la objeción ligada a la escasa participación que él y otros militantes sobrevivientes habían tenido en la concepción del texto: "merecíamos charlar... dos días, tres días, no una noche".

Del mismo modo, la introducción del personaje de "Pelusa" fue criticada por los sobrevivientes. Daleo refiere que su objeción se centró en la confusión que el personaje generaría entre los lectores y, en particular, entre familiares que acudieran al libro como fuente de información sobre detenidos que habían permanecido en la ESMA: "Alguna madre, algún padre que tuviera una hija a quien apodaban «Pelusa» podía pensar que era esa persona”. Subraya, así, "el peligro... que entraña meter en un libro que habla de una historia real, fehaciente, vivida..., algo que es una construcción del autor"19.

dictadura: "La novela tiene un falso final feliz, ya que el protagonista -en este caso, yo- se salva de la prisión, de los atentados que luego se planifican contra él, y por último se reúne con su familia. Pero el verdadero final de esa historia lo escribieron los miles de prisioneros asesinados... El libro que ha escrito Miguel Bonasso sobre este tema muestra necesariamente esa parcialidad" (CASTELLANOS 1984, p. 58).

${ }_{18}$ La crítica a la concepción "aparatista" de Recuerdo de la muerte fue planteada también por Roberto Perdía y Fernando Vaca Narvaja, integrantes de la conducción de Montoneros que en 1985 debatieron sobre el libro con el autor. Según ellos, el texto "escamoteaba la verdadera historia de las luchas montoneras, reduciéndolas a una guerra de aparatos" (BonAsso 1994, p. 461).

${ }_{19}$ En Mujeres guerrilleras, libro en que Marta Diana entrevista a mujeres exmilitantes de organizaciones político-militares (1996), la autora señala: 
Ahora bien: la discusión sobre el carácter novelado de Recuerdo de la muerte tenía todavía más implicaciones para los sobrevivientes que discutieron el libro con Bonasso. Era la dimensión factual del texto la que prevalecía frente a lectores que se veían retratados en él como "personajes": "Yo no lo leí como novela, estaba leyendo un pedazo de mi vida, y de la vida de mis compañeros y de mis compañeras", afirma Daleo a este respecto. Así, se distancia de una lectura del libro en clave de simple novela o ficción, lectura que llevaba a banalizar los hechos atroces que los sobrevivientes padecieron, ineludiblemente reales para ellos $^{20}$. Sin embargo, la sobreviviente repara en la complejidad que supone establecer los límites entre novela y testimonio, entre ficción y no ficción, ante un texto ambiguo como Recuerdo de la muerte: "Cuál es el límite, cuándo es ficción y cuándo es realidad...; cuándo es ficción, literatura y cuándo estás haciendo un trabajo testimonial, histórico", se interroga Daleo.

Para concluir este apartado, notemos que algunos de los problemas que los exdetenidos señalaron al autor en efecto tuvieron su realización en el proceso de recepción del libro. Por un lado, la abierta identificación de los protagonistas como militantes de Montoneros fue utilizada como argumento en defensa de los represores en el Juicio a las Juntas, de 1985. Jaime Prats Cardona, defensor de Massera, citó el texto en su alegato, para descalificar el testimonio de varios exdetenidos por su vínculo con dicha organización ${ }^{21}$. Años más tarde, Bonasso (2001a)

"Cada vez que alguien menciona la ESMA, surge el recuerdo, y generalmente la polémica, por el libro de Miguel Bonasso: Recuerdo de la muerte", y agrega que "el tema de los «amores prohibidos» que surgieron entre las mujeres y sus captores fue, sin duda, el que más desagrado produjo" (p. 149, cursivas en el original). En el mismo sentido, Miriam Lewin, también sobreviviente de la ESMA, plantearía años después una crítica al enfoque de Bonasso en el libro que publicó junto a Olga Wornat, Putas y guerrilleras (2014). Las autoras señalan allí la "visión machista, y algo maniquea" que orienta el relato de Bonasso y reparan en el carácter ambiguo del personaje de "Pelusa", el "único... que no lleva su nombre o nom de guerre real" (p. 111).

20 "Después vi que le daban un premio por novela negra... [y] se me pararon los pelos porque ¿novela negra? Ahí aparecemos con nombre y apellido...".

21 “...Si se pasa al libro de Miguel BONASO [sic] titulado «Recuerdos de la muerte» $[s i c]$, encontramos que BONASO, conspicuo dirigente montonero..., aparece repetidas veces integrando su conducción nacional en el exilio... Me parecen de interés algunas referencias que contiene ese libro... Dice BONASO: «...Un grupo de más de 50 prisioneros compuesto por antiguos dirigentes montoneros o viudas de militantes famosos de esa organi- 
admitiría la exposición que la publicación del libro había conllevado para muchos sobrevivientes, "en una Argentina donde se acababa de estrenar una democracia débil, todavía muy atenta a los malignos susurros que emanaban de bases y cuarteles" (p. 40). Por otro lado, también la ambigüedad del personaje de "Pelusa" generó confusiones, aunque no entre familiares de víctimas, como lo habían previsto los exdetenidos, sino entre los mismos perpetradores: ya a mediados de los años noventa, Adolfo Scilingo, exjefe de automotores de la ESMA, aludió a "Pelusa" en un programa televisivo, asumiendo erróneamente que se trataba de una persona real que había permanecido prisionera en aquel centro clandestino de detención ${ }^{22}$. Nos referiremos en el próximo apartado a la relectura de la que Recuerdo de la muerte fue objeto en la década de 1990, en un contexto de auge de los discursos memoriales sobre el pasado dictatorial, desatado a partir de la irrupción pública de la voz castrense.

¿NOVELA DE LAS TORTURAS? LA IRRUPCIÓN PÚBLICA DE LA VOZ DE LOS REPRESORES Y LA POLÉMICA ENTRE MASSERA Y BONASSO

A mediados de los años noventa, tuvo lugar una "explosión de la memoria” en la esfera pública (Crenzel 2016, p. 57) que resituó la cuestión del terrorismo de Estado en el centro del debate social, luego de la clausura provisoria del proceso de memoria, verdad y justicia que habían significado las leyes de Punto Final y Obediencia Debida sancionadas durante el alfonsinismo (1986 y 1987) y los indultos decretados por el expresidente Carlos Menem (1989 y 1990). Un elemento importante de este auge memorial lo constituyó la irrupción pública de la voz de los perpetradores, que comenzó en marzo de 1995, cuando el antes citado Adolfo Scilingo narró su participación en los lla-

zación, fueron liberados y desparramados por el mundo. Los últimos en transponer los portones de la ESMA, fueron Andrés CASTILLO y Graciela DALEO, obviamente están reconociendo que CASTILLO y DALEO eran montoneros»" ("Las defensas", p. 5).

${ }^{22}$ El episodio es evocado por Miriam Lewin en las conversaciones de mujeres sobrevivientes reunidas en Ese infierno: "Cuando Scilingo participó en el programa de televisión de Mariano Grondona nombró a Pelusa, que era un personaje imaginario, una licencia literaria del libro Recuerdo de la muerte. Hablaba de la situación de Pelusa como si hubiese ocurrido realmente y él hubiese sido testigo" (AcTis et al. 2001, p. 203). 
mados "vuelos de la muerte". Poco después, el entonces jefe del ejército Martín Balza pronunció un "Mensaje al país" en el que admitió la ilegitimidad de los actos de violencia de Estado perpetrados durante la dictadura (Salvi 2009, pp. 100 ss.).

En este contexto, Recuerdo de la muerte, a más de una década de su publicación original, y poco después de la publicación de la Edición definitiva (1994) ${ }^{23}$, volvió a ser objeto de debate. Entre julio y agosto del mismo año, Emilio Massera — quien había sido condenado en el Juicio a las Juntas y posteriormente liberado a partir de los indultos- realizó una serie de declaraciones en los medios de comunicación, que incluyeron entrevistas en la prensa gráfica y apariciones en radio y televisión. Massera se pronunció sobre los crímenes de Estado perpetrados durante la dictadura en términos que oscilaron entre la autojustificación y el negacionismo (Feld 2016). Tomando distancia de la proclama institucional de Balza, cuestionó que durante el "Proceso" existiese un dispositivo sistemático de exterminio y, en cambio, retomó el tópico de "la nación en guerra", fundante de la dictadura (Salvi 2009, p. 31), para reivindicar los secuestros y las torturas como métodos a los que las fuerzas armadas habrían recurrido en una situación social "extraordinaria".

Lo que interesa destacar de sus declaraciones es que, como ha señalado Claudia Feld (2016) para el caso del discurso televisivo de otro perpetrador, Miguel Etchecolatz, Massera buscó "reforzar sus propias mentiras acusando a sus víctimas de mentir y tratando de probar la culpabilidad de quienes lo acusan" (p. 99). En este sentido, intentó reabrir la discusión social sobre hechos previamente probados en la esfera judicial, y que entre diversos sectores sociales se daban por verdaderos, refiriéndose al Nunca más y a Recuerdo de la muerte como "novelas", y a la gran "fantasía" que la sociedad argentina habría elaborado sobre la represión clandestina en la dictadura:

Recuerdos de la muerte [sic] es... nada más que una novela. Una ficción hecha en base al relato de un colaborador de la ESMA. Escribe bien Bonasso. Ojalá lo pudiera contratar para que escriba para mí... ("Las confesiones...", p. 50).

${ }^{23}$ La Edición definitiva fue la quinta publicada en la Argentina. En ella Bonasso incorpora, como hemos señalado en el apartado anterior, el posfacio titulado "Paredón y después" (véase supra, "Entre el best seller y la discusión política...”). 
No hay ninguna duda de que [los centros de detención] existieron (pero) creo que se ha exagerado, es decir, la novela, como yo califico al Nunca Más de Sabato, es una exageración, donde un conjunto de personas hacen [sic] declaraciones que después no clarifican ante la Cámara Federal, algunos sí, pero se teje una novela de las torturas ("El retorno...", p. 10).

Desgraciadamente, nuestra sociedad tejió una fantasía, que no comenzó con Scilingo. Esta fantasía comenzó con el famoso cabo Villariño, quien hizo un alegato sobre las matanzas en la Escuela de Mecánica de la Armada..." ("La canción...", p. 9).

Massera: Tengo un caso de un hombre que trabaja para la Marina, que es Dri. Que Bonasso lo hace héroe de "Recuerdo de la muerte". Leí todo el libro de Bonasso... [Dri] Trabajaba como... trabajaban todos. Después resulta que son todos inocentes. Entonces Dri ha tejido una novela con Bonasso (Bonasso 1995 a, p. 32).

Las declaraciones de Massera suscitaron expresiones críticas y de repudio, no sólo de organizaciones de derechos humanos, sino también de intelectuales y periodistas, y hasta de figuras castrenses que tomaron distancia de su discurso. La Asociación de Ex Detenidos Desaparecidos sostuvo en un comunicado: "tenemos elementos para refutar cada palabra del asesino que disfrutó de dos horas de televisión. No vamos a hacerlo: los ex detenidos desaparecidos - testimonio vivo del horrorno polemizamos con torturadores" ("Bauzá...", p. 8). De este modo, buscaban anular el intento de Massera por reabrir la discusión sobre lo acaecido durante la dictadura, al desacreditar la verdad jurídica consagrada en el Juicio a las Juntas. Sin embargo, el contexto de impunidad garantizado por las políticas de justicia oficiales parecía "avalar una... puesta en cuestión permanente de esta verdad" (Feld 2016, p. 99).

En el mismo sentido, Sabato defendió la validez histórica del Nunca más, señalando que se trataba de "un informe fáctico, sin siquiera un adjetivo" ("Sabato rechazó...", p. 10), de una síntesis de "miles de páginas de testimonios recogidos por la CONADEP y que nadie en su sano juicio ha refutado" ("El retorno...", p. 10). El PEN Club Internacional se plegó a su descargo, señalando las consecuencias éticas y políticas de los dichos del exalmirante, pero también la tergiversación agraviosa que implicaban desde el punto de vista literario: "no sólo se trata de una ofensa 
a un novelista célebre sino a una dura etapa de la vida argentina contemporánea" ("Defiende...", p. 10).

En cuanto a Bonasso, el escritor se pronunció sobre las declaraciones de Massera en notas de opinión que publicó en el diario Página/12. Acerca de la descalificación que el excomandante hizo de su libro, argumentó que "quiere trivializar lo que el libro muestra, al decir que es nada más que una novela... Denigrarlo al presentarlo como el relato de «un colaborador» de la ESMA, sin decir que ese colaborador, Jaime Dri, se escapó del campo de concentración y lo denunció" (1995, p. 15). La respuesta de Bonasso resulta significativa porque identifica en los dichos de Massera dos aspectos de Recuerdo de la muerte que ya habían estado presentes en la discusión del autor con los sobrevivientes de la ESMA y que, en la discusión con el perpetrador, cobran un sentido diferente. Por un lado, la cuestión de la parcialidad del libro, que exaltaba la figura heroica de Dri: si para los exdetenidos el problema residía en que concentrar la atención en el prisionero fugado llevaba a eludir algunos de los aspectos más inhumanos de la experiencia concentracionaria, Massera apelaba, en cambio, al estigma del "colaborador" para desacreditar la denuncia que planteaba el libro con un argumento ad hominem, y situando en los propios detenidos la responsabilidad por lo ocurrido en la ESMA.

Por otro lado, la cuestión de la banalización de los hechos surgía en la crítica de Bonasso a Massera. Desde la perspectiva de los sobrevivientes, la calificación del texto como simple "novela" podía llevar a estetizar la violencia ejercida en la detención clandestina. El exdictador, en cambio, utilizaba el calificativo para cuestionar la factualidad de lo narrado en el libro, junto a toda una verdad jurídica y social sobre las violaciones a los derechos humanos en la dictadura, legitimada en los primeros años de la democracia y relativizada más tarde por las políticas de impunidad aplicadas desde el final de los años ochenta. Cabe notar, no obstante, que Bonasso discute la reducción de su libro a una novela, y no el empleo per se de este concepto para referirse al texto - como sí ocurrió, en cambio, en las réplicas a los dichos de Massera sobre el Nunca más, en virtud de su carácter inequívocamente testimonial. En efecto, tratándose de una "novela-real o realidad-novelada" (Bonasso 1984a, p. 397), la faceta novelesca del texto emergía ya en el pacto de lectura que el autor había formulado al concebir Recuerdo de la muerte. 


\section{Conclusiones}

La novela de no ficción es un género complejo. Si por un lado persigue la verdad, asumiendo un compromiso ético y en ocasiones político con el reporte riguroso de los hechos, por otro se propone la lectura como una producción artística, relativizando, bajo el resguardo que ofrecería la autonomía de la literatura, su subordinación a las lógicas de veridicción que imperan en el mundo ordinario. El modo en que se dirime la tensión entre uno y otro aspecto del género depende, en buena medida, de circunstancias sociales, que atraviesan tanto la producción como la recepción de estos textos. Así lo hemos intentado mostrar en el caso de Recuerdo de la muerte, cuya concepción y circulación en distintas etapas de la posdictadura argentina estuvieron atravesadas por las tensiones que conllevó el proceso de construcción de memoria, verdad y justicia sobre el terrorismo de Estado en la última dictadura militar. La recepción favorable y hasta encomiástica de la que el texto fue objeto entre vastos sectores, y la naturaleza canónica que alcanzó como denuncia de la represión dictatorial, contrastan con diversas discusiones que suscitó, primero en la transición democrática y luego en el contexto de la "explosión de la memoria" a mediados de los años noventa.

Lo que se puso en entredicho en la recepción del texto de Bonasso es, en primer lugar, la precisión con la que el libro representaba los hechos vinculados a la detención clandestina y, en esta línea, el valor de verdad de un texto que había sido presentado como "rigurosamente cierto" por su autor (Bonasso 1984a, p. 404). Se trataba, así, de objeciones que cuestionaban en qué medida el autor cumplía con una de las facetas del pacto abiertamente ambiguo de lectura que proponía con su "novela-real o realidad-novelada" (id.). Para los sobrevivientes de la ESMA, que habían conocido el dispositivo concentracionario desde adentro y se encontraban retratados en el libro como "personajes", era la parcialidad del enfoque de Bonasso lo que contrariaba sus pretensiones de rigor histórico. La atención volcada en la figura de Dri, y el hecho de que la novela se basase únicamente en su testimonio, desvirtuaban para los exdetenidos la cruda realidad que habían atravesado, no sólo por la excepcionalidad de la experiencia del protagonista —único prisionero de la ESMA que logró fugarse y sobrevivir-, sino además porque, al centrarse en su figura, el autor había eludido 
aspectos de la detención clandestina que revestían importancia en la transición democrática, como fundamentos de las denuncias de las violaciones a los derechos humanos impulsadas por exdetenidos y familiares de desaparecidos.

En segundo lugar, las polémicas sobre Recuerdo de la muerte plantean la cuestión de las implicaciones del (ab) uso estético de vidas reales para hacer literatura y, en particular, de la divulgación inconsulta de hechos reales asociados a los nombres propios de quienes los han protagonizado. Hemos visto, así, que la publicación del libro en los inicios de la democracia acarreaba cierta exposición para exdetenidos que habían sido militantes, en un entorno en que no sólo los perpetradores del terrorismo de Estado, sino también los integrantes de organizaciones guerrilleras, eran perseguidos por las políticas de justicia oficiales. En este punto, lo que se ponía en entredicho ya no era la veracidad del texto de Bonasso. Más bien, se cuestionaba el hecho mismo de que el autor sacara a relucir ciertas verdades sobre los exdetenidos en el contexto complejo de la transición democrática. Ahora bien, el abuso que, desde esta perspectiva, había constituido la publicación del libro no dejaba de estar en relación con el sesgo que algunos sobrevivientes observaban en él: se trataba del correlato de un proceso de elaboración literaria en el cual no habían tenido participación; de allí sus reparos sobre haberse vuelto, sin consentirlo, materia de la creación novelesca del autor.

Las polémicas sobre Recuerdo de la muerte aportan elementos de análisis para la discusión sobre el estatuto de la novela de no ficción como género literario. Muestran que la dualidad del género, tensionado entre su pretensión de verdad y su faceta artística, no constituye un mero rasgo formal de estos textos, sino que tiene efectos concretos en sus procesos de recepción. A la vez, las discusiones sobre el libro de Bonasso exponen la operatividad social, política y hasta ética de la categoría de no ficción y de su par opuesto, el concepto de ficción. En efecto, en estos debates los actores utilizan tales categorías para elaborar interpretaciones sobre el texto de Bonasso, en el marco de las disputas sociales por la producción de la verdad sobre los años setenta en la Argentina. La polémica entre el autor y el excomandante Massera cobra particular importancia en este punto. Frente al negacionismo del perpetrador, que buscaba reducir los crímenes de Estado cometidos en la dictadura a una "novela" construida en Recuerdo de la muerte y en otros discursos 
testimoniales y de denuncia, la defensa del carácter factual de dichas narrativas resultaba crucial, particularmente en un contexto de impunidad oficializada desde el Estado.

Ahora bien: si los debates en torno a Recuerdo de la muerte ponen de manifiesto la relevancia social de los conceptos de no ficción y ficción, asimismo evidencian la complejidad que involucra su definición cuando se los trata no como categorías abstractas, sino como prácticas narrativas concretas, producidas y recibidas en el seno de ciertos procesos sociales. Como señaló Genette (1991), la literatura despliega entrecruzamientos múltiples de lo factual y lo ficcional, que parecen desafiar las definiciones generadas en los "tubos de ensayo" de la teoría literaria (p. 79), pero que, a la vez, requieren de ellas para ser entendidos en su complejidad. El texto de Bonasso ofrece una muestra clara de ello: su ambivalencia entre lo novelesco y lo testimonial no sólo constituyó una apuesta deliberada del autor, orientada a popularizar los hechos, aun al precio de restar rigurosidad histórica al relato, sino que además permite explicar, al menos en parte, la recepción dispar de la que fue objeto el texto: que por un lado alcanzase una difusión masiva, para cumplir con los propósitos del autor, y, por otro, generase múltiples discusiones entre actores involucrados en las disputas sociales por la producción de verdad sobre las violaciones a los derechos humanos en la última dictadura militar.

\section{REFERENCIAS}

\section{Corpus}

Actis, Munú, Cristina Aldini, Liliana Gardella, Miriam Lewin y Elisa TOKAR 2001. Ese infierno. Conversaciones de cinco mujeres sobrevivientes de la ESMA, Sudamericana, Buenos Aires.

Bardini, Roberto 1984. "Miguel Bonasso", Humor, 123, pp. 62-65.

"Bauzá: «La sociedad ya lo juzgó»" 1995. Clarín, 9 de agosto, p. 8.

Blaustein, Eduardo 1988. "Reedición. Recuerdo de la historia”, Página/12, 6 de abril, p. 13.

Bonasso, Miguel 1984. "El infierno en la literatura argentina actual. Adelanto de Recuerdo de la muerte", Humor, 121, pp. 117-119.

Bonasso, Miguel 1984a. Recuerdo de la muerte, Bruguera, Buenos Aires.

Bonasso, Miguel 1985. "Nuevas pruebas contra Galtieri”, El Porteño, 43, pp. 20-22.

Bonasso, Miguel 1988. Recuerdo de la muerte, Puntosur, Buenos Aires. 
Bonasso, Miguel 1994. Recuerdo de la muerte. Edición definitiva, Planeta, Buenos Aires.

Bonasso, Miguel 1995. "En Massera, el discurso es el método. Bonasso contesta sin novela”, Página/12, 30 de julio, pp. 14-15.

Bonasso, Miguel 1995a. "Los insultos del verdugo", Página/12, 10 de agosto, p. 32.

Bonasso, Miguel 1999. "La verdadera historia del Tigre en la ESMA", Página/12, 3 de enero, en https:/ /www.pagina12.com.ar/1999/99-01/99-0103/pag03.htm [consultado el 10 de abril de 2019].

Bonasso, Miguel 2001. "Cómo escribí Recuerdo de la muerte", 3 puntos, 4, 200, pp. 32-33.

Bonasso, Miguel 2001a. "Con el Pelado en el laberinto", 3 puntos, 4, 203, pp. $40-41$.

Bonasso, Miguel 2014. Lo que no dije en "Recuerdo de la muerte", Sudamericana, Buenos Aires.

Castellanos, Luis 1984. "«Yo me escapé de la Escuela de Mecánica de la Armada» (entrevista a Jaime Feliciano Dri)", La semana, 392, 8 de junio, pp. 56-64.

"Defiende el PEN Club a Ernesto Sabato" 1995. La Nación, $1^{\circ}$ de agosto, p. 10.

Diana, Marta 1996. Mujeres guerrilleras. La militancia de los setenta en el testimonio de sus protagonistas femeninas, Planeta, Buenos Aires.

Dri, Jaime 1978. Testimonio de Jaime Dri. Movimiento Peronista Montonero, Consejo Superior de Montoneros, Secretaría de Prensa, Paris.

"El retorno de un asesino: ahora Massera sale por radio y TV" 1995. Página/12, 29 de julio, p. 10.

Fazio, Carlos 1980. "Jaime Dri: el montonero que escapó de la pesadilla", Proceso, 10 de mayo, en https://www.proceso.com.mx/128574/jaime-dri-el-montonero-que-escapo-de-la-pesadilla [consultado el $10 \mathrm{de}$ abril de 2019].

Fazio, Carlos 1984. "Aparece en México «Recuerdo de la muerte», de Miguel Bonasso", Proceso, 24 de noviembre, en https://www.proceso. com.mx/140001/aparece-en-mexico-recuerdo-de-la-muerte-de-miguel-bonasso [consultado el 10 de abril de 2019].

Gasparini, Juan 1988. Montoneros: final de cuentas, Puntosur, Buenos Aires.

Guagnini, Catalina y Graciela Lois 1988. Carta a Miguel Bonasso, 4 de abril, Memoria Abierta (Familiares C7.71), Buenos Aires.

"La canción del verdugo" 1995. Página/12, 8 de agosto, p. 9.

"Las confesiones de Massera" 1995. Gente, 1566, pp. 48-56.

"Las defensas" 1985. El Diario del Juicio, 1, 25, pp. 1-8.

Lewin, Miriam y Olga Wornat 2014. Putas y guerrilleras, Planeta, Buenos Aires.

Ramonet, Ignacio 1984. "Un roman de Miguel Bonasso", Le Monde Diplomatique, noviembre, p. 9, en https://www.monde-diplomatique.fr/1984/11/ RAMONET/38276 [consultado el 11 de marzo de 2019].

"Sabato rechazó las críticas de Massera" 1995. Clarín, 29 de julio, p. 10. 


\section{Referencias bibliográficas}

Amar Sánchez, Ana María 2008. El relato de los hechos. Rodolfo Walsh: testimonio y escritura, De la Flor, Buenos Aires.

BERG, EdgARdo 1995. "Fronteras móviles: consideraciones acerca de la producción narrativa de «no ficción» en la Argentina", Revista del Celehis, 4/5, pp. 93-105.

CaÏra, Olivier 2011. Définir la fiction. Du roman au jeu d'échecs, Editions de l'École des Hautes Études en Sciences Sociales, Paris.

Calveiro, Pilar 2008. Poder y desaparición. Los campos de concentración en Argentina, Colihue, Buenos Aires.

Cercas, Javier 2016. El punto ciego, Penguin Random House, Barcelona.

Clarke, Gerald 2006. Truman Capote. La biografía. Trad. Víctor Pozanco, Javier Vergara, Barcelona.

Coira, María 1995. "Versalles del horror", Revista del Celehis, 4/5, pp. 167183.

CONADEP = Comisión Nacional sobre la Desaparición de Personas 1984. Nunca Más. Informe de la Comisión Nacional sobre la Desaparición de Personas, EUDEBA, Buenos Aires.

Confino, Hernán 2015. "La contraofensiva estratégica montonera en las memorias de sus participantes. Crónica de un objeto polémico”, Aletheia, 6, 11, s.pp.

Crenzel, Emilio Ariel 2010. "La víctima inocente: de la lucha antidictatorial al relato del Nunca Más", en Los desaparecidos en la Argentina: memorias, representaciones e ideas (1983-2008). Dir. Emilio Crenzel, Biblos, Buenos Aires, pp. 65-84.

Crenzel, Emilio Ariel 2016. "Entre la historia y la memoria. A 40 años del golpe de Estado en la Argentina”, História: Questões Ẽ Debates, 64, 2, pp. 39-69; doi: 10.5380/his.v64i2.49733.

ERLL, Astrid 2012. Memoria colectiva y culturas del recuerdo. Estudio introductorio, Universidad de los Andes, Bogotá.

Feld, Claudia 2016. "El imposible debate entre víctimas y victimarios: notas sobre las declaraciones televisivas de Miguel Etchecolatz (1997)", Rubrica Contemporanea, 5, 9, pp. 77-101.

Feld, Claudia y Luciana Messina 2014. "En torno a la palabra testimonial de los sobrevivientes: testigos legitimados y denegados de los centros clandestinos de detención en Argentina”, Tramas, 41, pp. 43-77.

Fleury, BéAtrice et Jacques WAlter 2012. "Carrière testimoniale: un opérateur de la dynamique mémorielle et communicationnelle", ESSACHESS. Journal for Communication Studies, 5, 10, pp. 153-163.

Fludernik, Monika \& Marie-Laure Ryan 2019. "Factual narrative: An introduction", en Narrative factuality. A handbook, De Gruyter, Berlin-Boston, pp. 1-26.

Foster, DAvid 1995. Violence in Argentine literature. Cultural responses to tyran$n y$, University of Missoury Press, Columbia, MO.

Franco, Marina 2014. "La «teoría de los dos demonios»: un símbolo de la posdictadura en la Argentina", A Contracorriente, 11, 2, pp. 22-52.

Gamerro, Carlos 2015. "Facundo" o "Martín Fierro". Los libros que inventaron la Argentina, Sudamericana, Buenos Aires. 
García, Romina 2002. Ficción, testimonio y debate social. Acerca de "Recuerdo de la muerte" de Miguel Bonasso, Estanislao Balder, Mar del Plata.

García, Victoria 2016. "Testimonio y ficción en la narrativa de la postdictadura. Los relatos del sobreviviente-testigo", Revista Chilena de Literatura, 93, pp. 73-100.

García, Victoria 2017. "Teoría (y) política de la ficción”, Badebec. Revista del Centro de Estudios de Teoría y Crítica Literaria, 7, 14, pp. 212-239.

Genette, GÉrard 1991. Fiction et diction, Seuil, Paris.

Goicochea, Adriana 2008. El relato testimonial en la literatura argentina de fin de siglo, Universidad Nacional de La Plata, La Plata.

Gramuglio, María Teresa 2002. "Políticas del decir y formas de la ficción. Novelas de la dictadura militar", Punto de Vista, 74, 25, pp. 9-14.

Heinich, Nathalie 2005. "Les limites de la fiction", L'Homme, 175/176, pp. 57-76; doi: 10.4000/lhomme.29504.

Heinich, Nathalie et Jean-Marie Schaeffer 2004. Art, création, fiction. Entre sociologie et philosophie, Éditions Jacqueline Chambon, Nîmes.

Jelin, ElizABETH 2007. "Víctimas, familiares y ciudadanos/as: las luchas por la legitimidad de la palabra", Cadernos Pagu, 29, pp. 37-60; doi: 10.1590/ S0104-83332007000200003.

Lavocat, Françoise 2016. Fait et fiction. Pour une frontière, Seuil, Paris.

Longoni, Ana 2007. Traiciones. La figura del traidor en los relatos acerca de los sobrevivientes de la represión, Norma, Buenos Aires.

LoReti, Damián y Luis Lozano 2014. El derecho a comunicar. Los conflictos en torno a la libertad de expresión en las sociedades contemporáneas, Siglo XXI, Buenos Aires.

Marsh, Kelly 2013. "Empathy, authority, and the narrative ethics of Truman Capote's «La Côte Basque, 1965»", Journal of Narrative Theory, 43, 2, pp. 218-244.

Morales, Mario Roberto (coord.) 2001. Stoll-Menchú: la invención de la memoria, Consucultura, Guatemala.

Nofal, Rossana 2001. "El testimonio de la militancia montonera en la Argentina: Miguel Bonasso", Entrepasados. Revista de Historia, 10, 20/21, pp. 57-71.

Oliveira-Cézar, María 2000. "Un estudio sobre Recuerdo de la muerte, de Miguel Bonasso", América: Cahiers du CRICCAL, 1, pp. 149-157; doi: 10.3406/ameri.2000.1461.

Pettersson, Torsten 2005. "Components of literariness: Readings of Capote's In cold blood", en From text to literature. New analytic and pragmatic approaches. Eds. Stein Haugom Olson \& Anders Petterson, Palgrave Macmillan, New York, pp. 89-105.

Picornell, Mercé 2015. "Autoría, autoridad y verdad. Apuntes para una nueva lectura «en frío» de la polémica Menchú-Stoll”, Kamchatka. Revista de Análisis Cultural, 6, pp. 349-378; doi: 10.7203/KAM.6.7062.

Plimpton, George 1966. "The story behind a nonfiction novel", The New York Times, 16 de enero, en http:/ / www.nytimes.com/books/97/12/28/ home/capote-interview.html [consultado el 16 de febrero de 2019].

Pozzoni, Mariana 2012. "Recuerdo de la muerte de Miguel Bonasso: entre la denuncia y la autocrítica. Una mirada exílica”, Malas Artes. Revista de Teoría y Crítica de la Cultura, 1, pp. 23-35. 
Reati, Fernando 1985. Nombrar lo innombrable. Violencia política y novela argentina, 1975-1985, Buenos Aires, Legasa.

Reati, Fernando 2013. "Culpables e inocentes, héroes y traidores: representaciones de la violencia política en Argentina desde 1980 hasta el presente", en Memorias en tinta. Ensayos sobre la representación de la violencia politica en Argentina, Chile y Perú. Ed. Lucero de Vivanco Roca Rey, Universidad Alberto Hurtado, Santiago de Chile, pp. 81-106.

Ryan, MARIE-LAURe 2004. La narración como realidad virtual. La inmersión y la interactividad en la literatura y en los medios electrónicos, Paidós, Barcelona.

Salvi, Valentina 2009. De vencedores a víctimas. Relatos militares sobre el pasado reciente en la Argentina, Biblos, Buenos Aires.

SAPIRO, Gisèle 2013. "Droits et devoirs de la fiction littéraire en régime démocratique: du réalisme à l'autofiction", Revue Critique de Fixxion Contemporaine, 6, en http:/ / www.revue-critique-de-fixxion-francaise-contemporaine.org/rcffc/article/view/fx06.11/737 [consultado el 26 de mayo de 2019].

Sapiro, Gisèle 2016. La sociología de la literatura, Fondo de Cultura Económica, Buenos Aires.

Schaeffer, Jean-Marie 2002. ¿Por qué la ficción?, Lengua de Trapo, Madrid.

SchaefFer, Jean-Marie 2006. ¿Qué es un género literario?, Akal, Madrid.

SchaefFer, Jean-Marie 2013. "Fictional vs. factual narration", en The living handbook of narratology. Eds. Peter Hühn et al., Hamburg University Press, Hamburg, en https://www.lhn.uni-hamburg.de/node/56.html [consultado el 11 de marzo de 2019].

Schaeffer, Jean-Marie 2018. La experiencia estética, La Marca, Buenos Aires.

SEARle, John 1975. "The logical state of fictional discourse", New Literary History, 6, 2, pp. 319-332; doi: 10.2307/468422.

Strejilevich, Nora 2006. El arte de no olvidar. Literatura testimonial en Chile, Argentina y Uruguay entre los 80 y los 90, Catálogos, Buenos Aires.

Saer, Juan José 1997. El concepto de ficción, Seix Barral, Buenos Aires.

Tompkins, Phillip 1966. "In cold fact", Esquire, 55, 1 de junio, en https:// classic.esquire.com/article/1966/6/1/in-cold-fact [consultado el 6 de julio de 2020].

Vincenti, Roberto 2015. Crímenes y pecados: desbordes del relato de no ficción en la literatura argentina, tesis, Universidad de Buenos Aires, en http:/ / repositorio.filo.uba.ar/handle/filodigital/4284 [consultado el 11 de marzo de 2019]. 